\title{
Facioscapulohumeral dystrophy: jitter in facial
} muscles

\author{
J V TRONTELJ, J ZIDAR, M DENIŠLIČ, D B VODUŠEK, M MIHELIN \\ From the University Institute of Clinical Neurophysiology, University Medical Centre of Ljubljana, Yugoslavia
}

SUMMARY Motor end plate jitter was studied by single fibre EMG in the orbicularis oculi muscle of eight patients with facioscapulohumeral dystrophy activated by extramuscular nerve stimulation. The jitter was found to be slightly larger in comparison with the normal controls, although still within the normal limits in each patient. The findings are considered to indicate absence of any significant neuromuscular transmission disturbance, inflammatory or regenerative process, or reinnervation in progress. There was no evidence of muscle fibre conduction abnormality even in very weak muscle.

Facioscapulohumeral (FSH) dystrophy is a fairly well defined dominantly inherited muscle disease, with a characteristic distribution of muscle weakness and wasting predominantly in the shoulder girdle and face, with usual onset between 6 and 20 years of age, slow progression and often long periods of virtual arrest. Facial weakness develops early, presenting as inability to close the eyes firmly or purse the lips and whistle. The atrophy of the trapezii, sternal portion of the pectorales, and the sternomastoids, elevation of the scapulae due to weakness of the periscapular muscles, strikingly bulky and strong deltoids, atrophic arms with relatively preserved forearms ("Popeye look") result in a characteristic appearance. Another peculiar feature is the occasional congenital absence of a muscle (e.g. one pectoral or brachioradialis), or part of a muscle. The advancing disease also affects the trunk muscles, pelvic girdle, and, characteristically, the anterior tibial muscles. Late in the disease, the external ocular muscles may be affected, whereas heart involvement is rare. Progression may stop at any point. The serum CK is usually only mildly elevated. EMG demonstrates myopathic, and occasionally, neurogenic features. ${ }^{12}$

Single fibre EMG (SFEMG) has shown normal or mildly elevated fibre density, while the jitter tended to be rather abnormal in the extensor digitorum communis muscle, if the muscle was weak and particularly if atrophy was prominent. The muscle fibre propa-

Address for reprint requests: Professor Jože Trontelj, University Institute of Clinical Neurophysiology, Zaloška 7, 61105 Ljubljana, Yugoslavia.

Received 8 January 1988.

Accepted 7 March 1988 gation velocity tended to be lower than in other muscular dystrophies except that of Duchenne. Mildly involved muscles showed little abnormality in SFEMG. ${ }^{34}$

The purpose of this study was to evaluate the motor end plate function in FSH dystrophy as revealed by SFEMG, using the recently elaborated and standardised technique of jitter recording in the orbicularis oculi activated by extra-muscular electrical stimulation. ${ }^{5}$ The advantage of this method is that the interdischarge interval-dependent jitter due to so-called velocity recovery function (VRF) ${ }^{6}$ in the muscle fibres is eliminated. The VRF is occasionally prominent in myopathies ${ }^{4}$ and the contamination of the neuromuscular jitter by the VRF in conventional jitter study in voluntarily activated muscle may produce false abnormal values. The aim of this work was to see whether and to what extent the motor end plate function is affected by degenerative, inflammatory or regenerative processes identified histologically in this disorder.

\section{Patients and method}

Patients Eleven patients with FSH dystrophy, attending the Centre for Neuromuscular Disorders at the University Medical Centre of Ljubljana were studied. They were diagnosed according to the established clinical and laboratory criteria, including genetic evaluation, detailed muscle test, serum CK level, EMG, and muscle biopsy. All were in an advanced stage of their disease, and all had prominent facial weakness, including weak closure of the eyes. Three of them had their orbicularis oculi muscle so weak and wasted that adequate numbers of single fibre recordings could not have been sampled without great difficulty and unacceptable discomfort for the patient, and they had to be excluded. The details on the remaining eight patients are given in table 1 . 
Table 1 Clinical data on the eight patients with FSH dystrophy included in the study

\begin{tabular}{|c|c|c|c|c|c|c|c|c|c|c|}
\hline $\begin{array}{l}\text { Patient No } \\
\text { sex \& age }\end{array}$ & $\begin{array}{l}\text { Familial } \\
\text { occurrence }\end{array}$ & $\begin{array}{l}\text { Age at } \\
\text { onset }\end{array}$ & $\begin{array}{l}\text { Disability } \\
\text { grade }^{8}\end{array}$ & $\begin{array}{l}\text { Facial } \\
\text { weakness }\end{array}$ & $\begin{array}{l}\text { Serum } \\
\text { CK† }\end{array}$ & $E M G_{+}^{+}$ & $F D$ & $\begin{array}{l}S F E M G \S \\
M I S I\end{array}$ & Jitter & Muscle biopsy \\
\hline $\begin{array}{llll}1 & F & 13 & y \\
2 & M & 20 & y\end{array}$ & $\begin{array}{l}\text { yes } \\
\text { yes }\end{array}$ & $\begin{array}{r}6 y \\
13 y\end{array}$ & $\begin{array}{l}3 \\
3\end{array}$ & $\begin{array}{l}\text { moderate } \\
\text { moderate }\end{array}$ & $\begin{array}{l}190 \\
479\end{array}$ & $\begin{array}{l}\text { D } \mathbf{M} \mathbf{L} \\
\mathrm{D} \mathbf{M} \mathbf{L}\end{array}$ & $\begin{array}{l}1.8 \\
1.6 \\
1.8\end{array}$ & $\begin{array}{l}1.1 \\
0.9 \\
0.9\end{array}$ & $\begin{array}{l}10 \\
\mathrm{~N} \\
45 \% \text { (biceps) }\end{array}$ & $\begin{array}{l}\text { not done } \\
\text { dystr. changes }\end{array}$ \\
\hline $\begin{array}{llll}3 & F & 21 & y \\
4 & M & 29 & y \\
5 & M & 37 & y \\
6 & M & 40 & y\end{array}$ & $\begin{array}{l}\text { yes } \\
\text { yes } \\
\text { unknown } \\
\text { yes }\end{array}$ & $\begin{array}{l}14 y^{*} \\
19 y \\
26 y \\
17 y\end{array}$ & $\begin{array}{l}2 \\
3 \\
3 \\
3\end{array}$ & $\begin{array}{l}\text { severe } \\
\text { moderate } \\
\text { moderate } \\
\text { moderate }\end{array}$ & $\begin{array}{l}292 \\
429 \\
129 \\
120\end{array}$ & $\begin{array}{l}-\mathbf{M}- \\
-\mathbf{M}- \\
\mathbf{D} \mathbf{M}- \\
-\mathbf{M ~ L}\end{array}$ & $\begin{array}{l}2 \cdot 1 \\
2 \cdot 2 \\
2 \cdot 2 \\
2 \cdot 4\end{array}$ & $\begin{array}{c}\text { not done } \\
0.8 \\
1.0 \\
0.6 \\
1.1\end{array}$ & $\begin{array}{l}13 \% \\
25 \% \\
\mathrm{~N} \\
33 \% \text { (tib. ant.) }\end{array}$ & $\begin{array}{l}\text { not done } \\
\text { dystr. changes } \\
\text { dystr. + infl. } \\
\text { dystr. changes }\end{array}$ \\
\hline $\begin{array}{llll}7 & M & 41 & y \\
5 & F & 62 & y\end{array}$ & $\begin{array}{l}\text { unknown } \\
\text { unknown }\end{array}$ & $\begin{array}{l}32 y^{*} \\
26 y^{*}\end{array}$ & $\begin{array}{l}2 \\
4\end{array}$ & $\begin{array}{l}\text { severe } \\
\text { severe }\end{array}$ & $\begin{array}{l}117 \\
165\end{array}$ & $\frac{M-}{\mathrm{D} \mathbf{M}}$ & $\begin{array}{l}2 \cdot 1 \\
2 \cdot 5 \\
1 \cdot 7\end{array}$ & $\begin{array}{l}0.9 \\
0.9 \\
0.6\end{array}$ & $\begin{array}{l}10 \% \\
N \\
15 \% \text { (biceps) }\end{array}$ & $\begin{array}{l}\text { small ang. fibr. } \\
\text { small ang. fibr. }\end{array}$ \\
\hline
\end{tabular}

* Facial weakness since childhood.

†Upper normal limit of serum CK $=150$.

$\ddagger \mathrm{D}=$ prominent fibrillation, positive sharp waves, repetitive discharges; $\mathbf{M}=$ myopathic motor unit potentials; $\mathbf{L}=$ large motor unit potentials.

$\S$ FD = fibre density (normal <1.8), MISI = mean interspike interval (normal <0.8 ms). Jitter: in EDC unless specified otherwise; \% indicates percentge of abnormal readings, $\mathbf{N}=$ normal study.

\|Biopsy: dystr. = typical dystrophic changes; infl. = pronounced inflammatory changes.

They were aged between 13 and 62 years, mean 33 years. A family history of one or several similarly affected relatives diagnosed to have FSH dystrophy, with two cases of a milder, previously unrecognised form of the disease, was obtained in five of the eight patients. In families of the remaining three patients, existence of a mild or abortive form of the disease was suspected but could not be proved as they were not available for examination. The age at onset ranged from 6 to 26 years, mean 19 years: however, three of the patients apparently had facial weakness since early childhood, as they had never been able to purse their lips or whistle. Apart from facial weakness, detailed muscle testing using the MRC scale revealed a typical pattern of limb and trunk weakness, similar for all patients. There was marked involvement of the periscapular and humeral muscles, as well as significant weakness of trunk flexors and rotators, and the tibialis anterior was affected in all but one, to a degree causing high steppage gait in two. The pelvic girdle weakness produced moderate functional disability of grades 2-4 on Vignos and Archibald's scale, as modified by Walton. ${ }^{8}$ Muscle biopsy done in six of the eight patients, including routine histochemical stainings and electron microscopy, was considered typical of muscular dystrophy in four cases, revealed significant inflammatory changes in addition to those consistent with muscular dystrophy in one case, and focal small angulated fibres as a main finding in a further two cases, thought to be compatible with FSH dystrophy. Serum CK levels were normal in two patients, and mildly or moderately elevated in six. Coaxial needle EMG of shoulder and arm muscles showed a significant amount of fibrillation and positive sharp waves with occasional prominent high frequency repetitive discharges in three patients, "myopathic" mofor unit potentials in all, and large motor unit potentials in three. SFEMG in voluntarily activated extensor digitorum communis, occasionally also in biceps, brachioradialis, and tibialis anterior, showed normal or mildly elevated fibre density, and moderately prolonged mean interspike interval in at least one muscle. The jitter as studied in the standard way was normal (in three muscles) or moderately abnormal (in nine muscles, at least one in each patient); the percentage of abnormal recordings with or without blocking ranged from
10 to 45 . The findings were usually but not invariably more abnormal in the more affected muscles.

Method The jitter was measured in the orbicularis oculi muscle activated by extramuscular nerve stimulation. ${ }^{5}$ A pencil-shaped surface stimulating cathode with a blunt point was used to find a low threshold site on the zygomatic arch where several discrete facial nerve branches pass on their way to the orbicularis oculi muscle. Stimulation at this point produced small twitches in the lateral quadrant of the orbital portion of the orbicularis oculi muscle, often also in the upper or lower palpebra. A monopolar steel needle electrode, insulated with Tefion up to $1 \mathrm{~mm}$ from the tip (Teca MF37), was then inserted subcutaneously at this site. In some cases, the surface stimulating electrode was used throughout the study: however, although the jitter was unaffected by the choice of the electrode, the surface cathode tended to cause some discomfort after a while, owing to continuous pressure against the bone, and needle stimulation was preferred. The anode was a flexible strip electrode in a Velcro sleeve (Medelec GE-V 53058), loosely attached around the neck. The stimulus was a $50 \mu$ s rectangular pulse delivered by a Medelec SC6 voltage output stimulator with a ten-turn potentiometer to allow fine control of stimulus amplitude, and it was presented at $10 \mathrm{~Hz}$.

A thin Medelec single fibre electrode (SF 25 53051) was inserted intothe twitching part of the muscle, typically about $10 \mathrm{~mm}$ lateral to the outer canthus, about $15-25 \mathrm{~mm}$ up and medially from the stimulating cathode. The recording was made by a Medelec MS6 electromyograph, from which the analogue output was fed through a Tektronix 565 oscilloscope serving as voltage discriminator into a home-made microprocessor-based jittermeter. ${ }^{9}$ The filters were set to $3 \cdot 2$ $\mathrm{KHz}$ and $16 \mathrm{KHz}$, respectively. The action potentials were accepted for measurement if they corresponded to the usual single fibre criteria (stable shape, peak to peak amplitude more than $0.2 \mathrm{mV}$, rise time less than $0.3 \mathrm{~ms}$ ), and were undisturbed by responses of other fibres. The stimulus amplitude was carefully adjusted to be well suprathreshold in order to avoid the jitter of the stimulated point on the axon. ${ }^{9}$

The jitter was measured on-line as variability (mean consecutive difference, MCD) of the latency of consecutive 

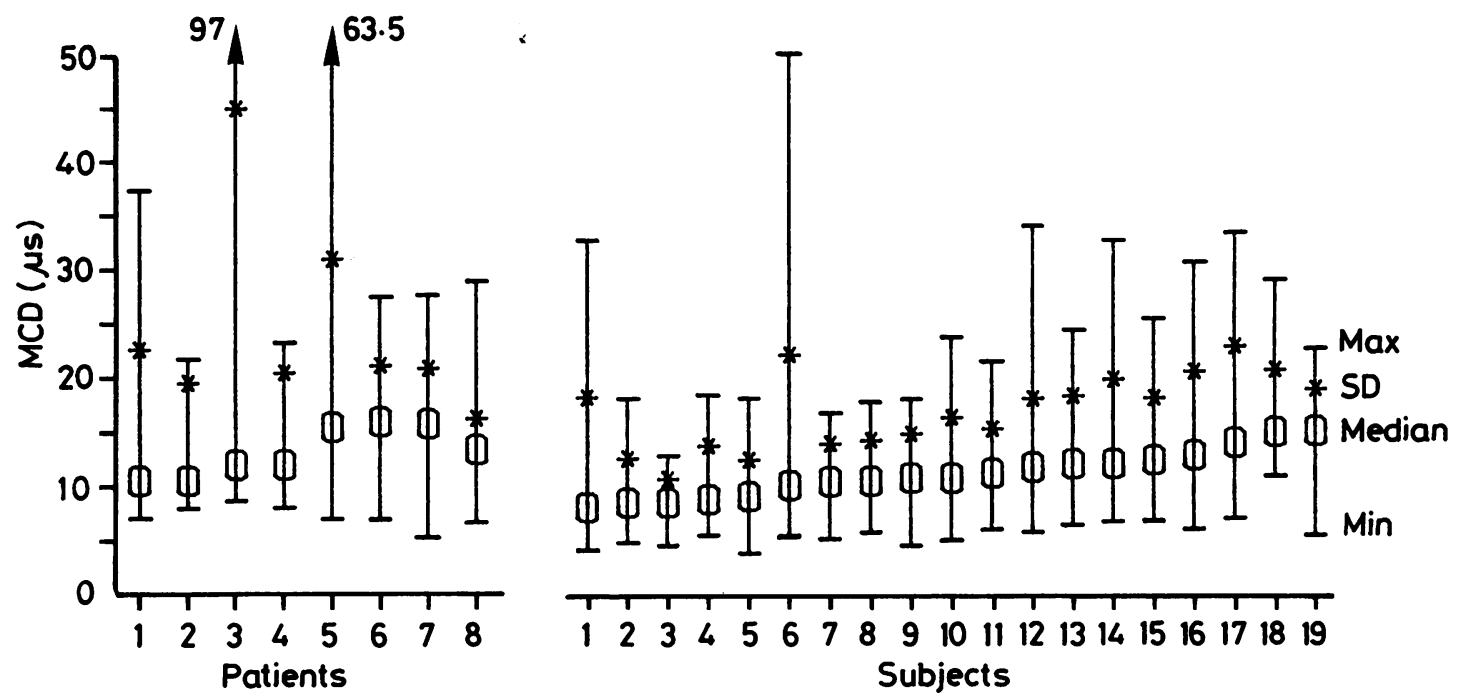

Fig 1 The jitter (MCD) in orbicularis oculi of the eight patients with FSH dystrophy, compared with 19 normal subjects in the same age group. ${ }^{5}$ Mean MCD (circles), SD (between circles and asterisks), and ranges (between dashes).

single fibre responses, at a resolution of 1 or $0 \cdot 1 \mu \mathrm{s}$. Five to seven series of 50 responses were acquired for each of about 20 single muscle fibres. The adequacy of the stimulus and the quality of the recording were carefully monitored on the screen throughout data acquisition. The latency of the recorded single fibre responses was also recorded. From each of the four or five recording sites, five to 10 different muscle fibres could usually be sampled. For other details of stimulation and recording technique and of jitter measurement see ref. $^{5}$

Of the five MCD values obtained for each muscle fibre, the mean value was computed from the lowest three. If, however, their range differed by more than $20 \%$ of the mean, and exceeded $5 \mu \mathrm{s}$, all data on that muscle fibre were rejected, on the assumption that the quality of stimulation or recording was not satisfactory. This was seldom necessary, not more than once per patient.

\section{Results}

The results of the eight patients are shown in comparison to normal material ${ }^{5}$ in figs 1 and 2 and in table 2 . The FSH patients had only slightly larger jitter than normal, but the difference was significant for the group, both when comparing pooled data for all the muscle fibres and means of individual patients $(0.001<p<0.005)$. All the individual patients had their median MCD values below the upper normal limit (18 $\mu \mathrm{s})$, and none had more than one motor end plate with an MCD above $30 \mu \mathrm{s}$, so all were normal according to both criteria. ${ }^{5}$

Figure 3 shows the relationship between the jitter and the latency of single fibre responses. There was a statistically significant correlation between these two parameters $(\mathrm{r}=0.25, t=3.1,0.001<\mathrm{p}<0.005)$, comparable with the normals $(\mathrm{r}=0.32, t=7 \cdot 6, \mathrm{p}<$ 0.001 ). The mean latency of $4.9 \mathrm{~ms}$ was identical to that in the normal controls.

\section{Discussion}

Increased jitter is not only a feature of disorders of neuromuscular transmission, but is a nonspecific finding in many neuromuscular disorders ${ }^{4}$ indicating disturbed motor end plate function. Thus jitter is increased not only in all neurogenic conditions with on-going denervation and collateral reinnervation, ${ }^{411}$ but also in primary muscle disorders such as muscular dystrophies and certainly in polymyositis, ${ }^{341213}$ that is, in all conditions where rearrangement in the internal architecture of the motor unit occurs. In muscular dystrophies the increased jitter is hypothetically explained with similar processes as the increase in fibre density, that is new innervation of regenerating muscle fibres, reinnervation of the segment of muscle fibre disconnected from the portion with the motor end plate by focal necrosis, reinnervation of muscle fibres denervated due to a neurogenic cause, and, under certain coniditions, liminal ephaptic recruitment of neighbouring muscle fibres of other motor units. ${ }^{4}$ The possibility of "myogenic" jitter due to a focal damage of the muscle fibre membrane resulting in impaired conduction of muscle fibre action potential has so far not been systematically investigated with SFEMG.

The finding of neurogenic EMG picture as well as 


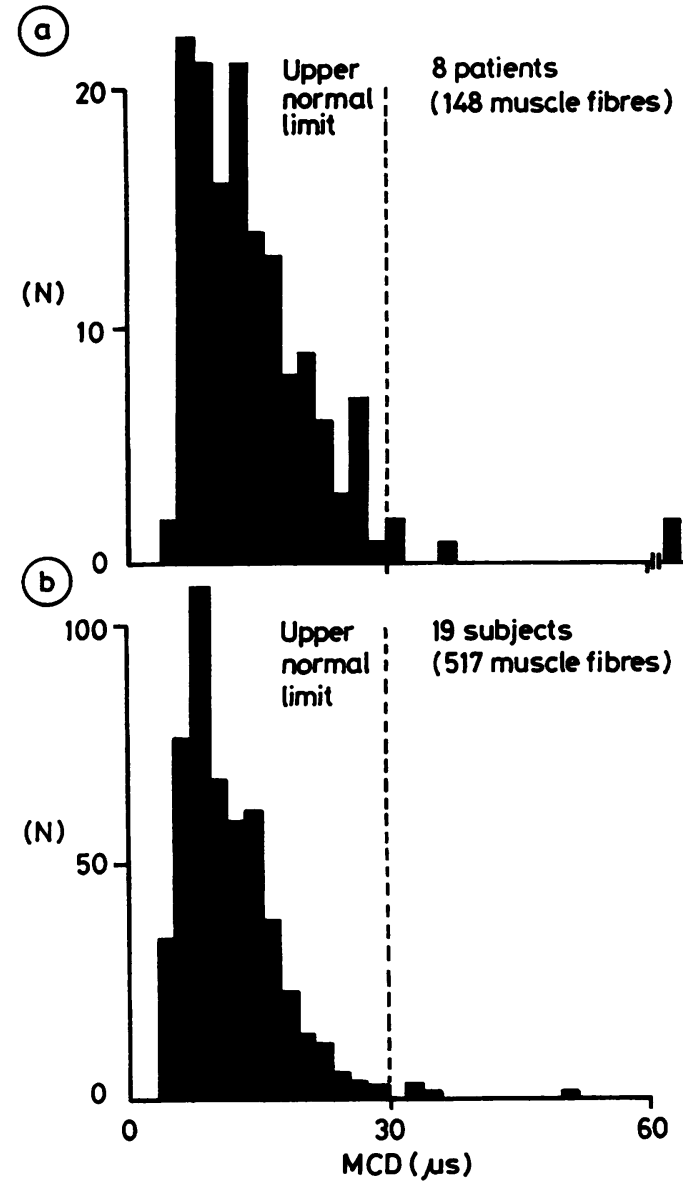

Fig 2 Pooled MCD values for all muscle fibres of all patients $(A)$, shown in comparison to collected material in 19 normal subjects. ${ }^{5}$ The dotted line indicates the upper normal limit (close to mean, $3 S D$ ).

Table 2 The jitter of the orbicularis oculi muscle fibres in eight patients with FSH, compared with the values obtained in 19 normal subjects 5

\begin{tabular}{|c|c|c|c|}
\hline & FSH patients & Normal subjects & $p$ \\
\hline \multirow{2}{*}{$\begin{array}{l}\text { No of muscle fibres } \\
\text { MCD-pooled data }(\mu \mathrm{s}) \\
\text { mean } \\
\text { SD } \\
\text { range }\end{array}$} & 148 & 517 & \multirow[b]{2}{*}{$<0.0001$} \\
\hline & $\begin{array}{l}15 \cdot 5 \\
10 \cdot 1 \\
5 \cdot 3-97 \cdot 0\end{array}$ & $\begin{array}{l}12 \cdot 4 \\
5 \cdot 6 \\
4 \cdot 0-50 \cdot 6\end{array}$ & \\
\hline $\begin{array}{l}\text { MCD-individual patient } \\
\text { mean of median MCDs } \\
\text { SD } \\
\text { range }\end{array}$ & $\begin{array}{l}\text { s/subjects } \\
13 \cdot 2 \\
2 \cdot 3 \\
10 \cdot 5-16 \cdot 0\end{array}$ & $\begin{array}{l}11 \cdot 4 \\
2 \cdot 2 \\
8 \cdot 3-15 \cdot 4\end{array}$ & NS \\
\hline $\begin{array}{l}\text { Per cent of individual } \\
\text { fibres above normal } \\
\text { limit }(30 \mu \mathrm{s})\end{array}$ & $3 \cdot 4^{*}$ & $0.8^{*}$ & \\
\hline
\end{tabular}

*Up to $5 \%$ acceptable as normal. some variation in clinical presentation has led some authors to suspect that the clinical picture of FSH may in fact comprise more than one nosological entity. Furthermore, weakness in facioscapulohumeral and pelvic-peroneal distribution may occur in several other disorders, so confusion with limb-girdle dystrophy, scapulo-peroneal dystrophy, chronic polymyositis, and spinal muscular atrophy of the scapuloperoneal distribution is possible, while the differential diagnosis also includes disorders like myotubular, nemaline and mitochondrial myopathy, central core disease and myasthenia gravis. ${ }^{1,2,16-19}$ Most of these possibilities could be ruled out in our cases by their classical distribution of pronounced muscle weakness and wasting, genetic pattern, enzyme study, EMG, and, in a majority, by muscle biopsy. SFEMG ruled out neurogenic and neuromuscular transmission disorders. We consider therefore that our cases belong to the classical FSH dystrophy.

Concentric needle EMG findings in FSH dystrophy are described as somewhat variable, ${ }^{2}$ with common fibrillation potentials, occasional complex repetitive discharges, and, apart from the usual typical myopathic unit action potentials, large units and reduced interference pattern in some patients, suggestive of a neurogenic disturbance. With single fibre EMG, the motor unit fibre density was normal in the biceps brachii, a severely affected muscle, in three patients and normal or moderately elevated in the extensor digitorum communis in four patients. ${ }^{3}$ However, the jitter was abnormal in 22 to $65 \%$ of the recordings. Our EMG and SFEMG findings in the limb muscles correspond rather well to the quoted reports and were considered consistent with the diagnosis. The occasional finding of large motor unit potentials in concentric needle EMG may be, at least in part, due to hypertrophic muscle fibres, ${ }^{13}$ and thus not necessarily a neurogenic phenomenon. The weaker muscles tended to show more EMG and SFEMG abnormalities.

Among the findings in muscle biopsy relevant for the understanding of the electrophysiological phenomena are the increased variability in fibre size, (however mainly due to the presence of hypertrophied rather than small diameter fibres ${ }^{14}$ ), scattered very atrophic angulated fibres strongly reactive in oxydative enzyme technique, ${ }^{14}$ 15 focal necrosis, phagocytosis and regeneration in the early stage, striking inflammatory changes with prominent regenerative activity at a later stage, later still followed by increasing fibrosis. ${ }^{1516}$

In SFEMG, one would expect these morphological features to be associated with increased mean interspike interval (increased fibre diameter variation), increased fibre density (denervation followed by collateral reinnervation, new innervation of regenerating 
(a)

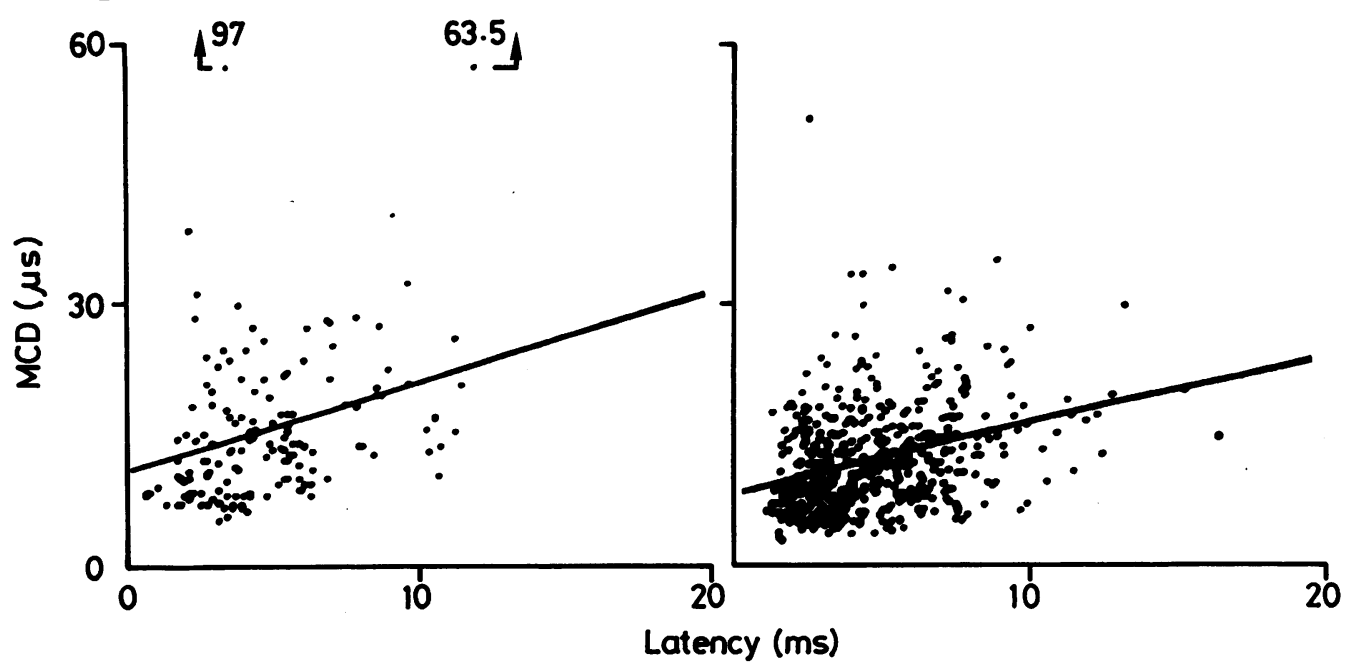

Fig 3 The jitter values (MCD) plotted against the latency for the individual muscle fibres. A: FSH patients, B: normal subjects.

fibres), increased jitter with or without blocking (collateral reinnervation and new innervation as long as the newly formed axonal twigs and end-plates are functionally immature, inflammatory process). Increased jitter might therefore be a regular finding throughout the active stage of the disease.

In the light of the above reports, our finding of normal jitter even in clinically very weak muscles of FSH patients seems unexpected. A small, although statistically significant difference to the normal material could only be detected when comparing pooled data from all muscle fibres studied. None of our patients was examined at an early stage of his or her disease, nor had the abortive form. Some were seen during an active progression, with serum CK levels 2-3 times the upper normal limit, while in others the disease was at an advanced stage but progression was considered slow (all patients had more or less regular follow-up manual muscle tests at 1-3 year intervals). The orbicularis oculi muscle was affected in all, the weakness ranging from moderate to very severe. Nevertheless the median MCD values were well within the limits of normal ${ }^{5}$ in all our patients, and even the patients did not differ from the normal material as a group.

The different methods used might be one of the possible reasons for the apparent discrepancy between the earlier SFEMG findings and the present study, and also between our own findings with the standard SFEMG method in limb muscles (table 1) and the results in the orbicularis oculi muscle in identical patients. It is known that muscle fibre velocity recovery function can be abnormally pronounced in muscular dystrophies, producing interdischarge interval dependent jitter which tends to contribute to the total jitter measured in voluntarily contracted muscle, particularly when interpotential interval is longer than 3-4 ms (as often happens in muscular dystrophies) ${ }^{4}$ and the innervation rate is irregular. Even the physiological degrees of irregularity may under these circumstances produce a significant myogenic jitter, which is difficult to estimate. A statistical method has been designed to eliminate the interdischarge interval dependent jitter (computation of the mean sorted interval, MSD, to replace MCD). However the effectiveness of this method is reduced by the fact that the innervation rate irregularity is superimposed with trends rather than being truly random. ${ }^{19}$ These problems are circumvented by the use of electrical stimulation, and with this method one can reasonably expect a jitter study in myopathy to produce lower values than standard SFEMG examination. However the differences in the jitter of this degree can probably not be accounted for by the different technique. Intermittent blocking that was also seen in cases of very abnormal jitter with standard SFEMG can certainly not be an artefact of the technique.

The choice of muscles studied seems to be a more important source of difference. It is not clear whether a facial muscle can be compared in this disorder, without any restriction, to a limb muscle such as the 
biceps brachii or extensor digitorum communis. It is possible that regeneration or inflammatory changes are less prominent in the facial muscles. Moreover, the process may have been arrested or burnt out in the facial muscles (which are among the first to be affected, often preceding limb muscles by years) even when other muscles showed evidence of progression. In some of our patients, standard SFEMG examination performed on the same day in two muscles showed abnormal jitter in one and normal in the other, sometimes weaker, muscle.

In conclusion, the barely noticeable deviation of jitter from the normal values suggests that at least at the time of examination our patients had no appreciable disturbance of neuromuscular transmission in the studied muscle, and therefore also no prominent inflammatory or regenerative activity, and no reinnervation in progress. Not only were the motor end plates practically normal, but also the muscle fibres even in clinically very weak muscles conducted their action potentials at a normal velocity (as the latencies did not differ from the normal material ${ }^{5}$ ) and with no detectable abnormal myogenic jitter. The study thus supports a previous impression that even severely weak muscles in FSH dystrophy, both in the active and in the late stage of the disease, may show little evidence for regenerative processes, ${ }^{13}$ which is in contrast to other forms of muscular dystrophy.

The authors are grateful to the patients for their cooperation. Miss Tatjana Gorjanc assisted with SFEMG examinations. Financial support was provided by the Research Community of Slovenia (grant No. C3-0558-306-87).

\section{References}

1 Walton JN, Gardner-Medwin D. Progressive muscular dystrophy and the myotonic disorders. In: Walton NJ, ed. Disorders of Voluntary Muscle. 4th ed, Edinburgh: Churchill Livingstone, 1981:502-5.

2 Swash M, Schwartz MS. Neuromuscular Diseases. A Practical Approach to Diagnosis and Management. Heidelberg: Springer-Verlag, 1981:174-6.

3 Stalberg E. Electrogenesis in human dystrophic muscle. In: LP Rowland, ed. Pathogenesis of Human Muscular Dystrophies. Proc. of 5th Internat. Conf. of the Muscular Dystrophy Ass. Amsterdam: Oxford, Excerpta Medica, 1977:570-8.
4 Stälberg E, Trontelj JV. Single Fibre Electromyography. Old Woking, Surrey: Mirvalle Press, 1979:1-244.

5 Trontelj JV, Khuraibet A, Mihelin M. The jitter in stimulated orbicularis oculi muscle: technique and normal values. J Neurol Neurosurg Psychiatry. (In press.)

6 Stälberg E. Propagation velocity in human muscle fibres in situ. Acta Physiol Scand 1966;70 Suppl 287:60-77.

7 Mihelin M. Automatic recognition and diagnostics in single fibre EMG. DSc Thesis, University of Ljubljana, 1983:1-116.

8 Walton JN. Clinical examination of the neuromuscular system. In: Walton JN, ed. Disorders of Voluntary Muscle. 4th ed. Edinburgh: Churchill Livingstone, 1981:448-80.

9 Trontelj JK, Mihelin M, Pleterek K, Antoni L. Jittermeter: a microcomputer-based system for single fibre electromyography. Int J Biomed Comput 1979;10: 451-9.

10 Trontelj JV, Mihelin M, Fernandez JM, Stälberg E. Axonal stimulation for end-plate jitter studies. $J$ Neurol Neurosurg Psychiatry 1986;49:677-85.

11 Stälberg E, Schwartz MS, Trontelj JV. Single fibre electromyography in various processes affecting the ventral horn cell. J Neurol Sci 1975;24:403-15.

12 Stälberg E, Trontelj JV, Janko M. Single fibre EMG findings in muscular dystrophy. In: Hausmanowa Petrusewicz I, Jedrzejowska H, eds. Structure and Function of Normal and Diseased Muscle and Peripheral Nerve. Warsaw: Polish Medical Publishers, 1974:185-90.

13 Stälberg E, Trontelj JV. Clinical neurophysiology: The motor unit in myopathy. In: Rowland LP, ed. Diseases of Muscle. Vinken PJ and Bruyn GW, eds. Handbook of Clinical Neurology, revised series, Amsterdam: North Holland Publ Co.; in press, 1987.

14 Dubowitz V, Brooke MH. Muscle Biopsy: a Modern Approach. London: Saunders, 1973.

15 Dubowitz V. Histochemical aspects of muscle disease. In: Walton JN, ed. Disorders of Voluntary Muscle. 4th ed. Edinburgh: Churchill Livingstone, 1981:261-95.

16 Munsat TL, Piper D, Cancilla P. Inflammatory myopathy with facioscapulohumeral distribution. Neurology 1971;22:335-47.

17 Thomas PK, Schott GD, Morgan-Hughes JA. Adult onset scapuloperoneal myopathy. J Neurol Neurosurg Psychiatry 1975;38:1008-15.

18 Ricker K, Mertens H-G. The differential diagnosis of the myogenic (facio)-scapulo-peroneal syndrome. Eur Neurol 1968;1:257-74.

19 Rothstein TL, Carlson CB, Sumi SM. Polymyositis with facioscapulohumeral distribution. Arch Neurol 1971; 25:313-9. 